\title{
Bag3 promotes resistance to apoptosis through Bcl-2 family members in non-small cell lung cancer
}

\author{
YONG ZHANG $^{1 *}$, JIAN-HUA WANG ${ }^{2 *}$, QIANG LU ${ }^{1}$ and YUN-JIE WANG ${ }^{1}$ \\ ${ }^{1}$ Department of Thoracic Surgery, Tangdu Hospital, The Fourth Military Medical University, \\ Xi'an 710038; ${ }^{2}$ Department of Thoracic Surgery, Affiliated Hospital, Shaanxi \\ Traditional Chinese Medical College, Xianyang 712000, P.R. China
}

Received June 7, 2011; Accepted August 16, 2011

DOI: $10.3892 /$ or.2011.1486

\begin{abstract}
In non-small cell lung cancer (NSCLC) certain molecular characteristics, which are related to molecular alterations have been investigated. These are responsible for both the initiation and maintenance of the malignancy in lung cancer. The aim of this study was to evaluate the influence of Bag3 (Bcl-2 associated athanogene 3 ) in the regulation of apoptosis on NSCLC. Bag3 and Hsp70 expression were examined by immunohistochemistry to confirm their potential roles in the prevalence of NSCLC. We also established human normal bronchial epithelial cells and HOP-62 cell line as the model to analyze cell apoptosis and the expression of $\mathrm{Hsp} 70, \mathrm{Bcl}-\mathrm{X}_{\mathrm{L}}$ and $\mathrm{Bcl}-2$, which were affected by Bag3. In this study, we found that Bag3 and Hsp70 are highly expressed in few tissues and cell lines of NSCLC. Bag3 inhibits apoptosis in human normal bronchial epithelial cell lines and sustain the survival of NSCLC cells. Bag3, Hsp70, Bcl-X $\mathrm{L}_{\mathrm{L}}$ and Bcl-2 are up-regulated in NSCLC cell lines. At the same time, the silencing of Bag3 results in diminishing protein levels of $\mathrm{Bcl}-\mathrm{X}_{\mathrm{L}}$ and $\mathrm{Bcl}-2$. The results of immunoprecipitation identified that $\mathrm{Bag} 3$ could interact with $\mathrm{Hsp} 70, \mathrm{Bcl}-\mathrm{X}_{\mathrm{L}}$ and Bcl-2 NSCLC cells directly or indirectly. We conclude that NSCLC cells were protected from apoptosis through increasing $\mathrm{Bag} 3$ expression and consequently promoted the expression of $\mathrm{Bcl}-\mathrm{X}_{\mathrm{L}}$ and $\mathrm{Bcl}-2$.
\end{abstract}

\section{Introduction}

Lung cancer has the highest mortality rate in the world $(1,2)$. It is a malignancy arising from different histology types of

Correspondence to: Dr Qiang Lu or Professor Yunjie Wang, Department of Thoracic Surgery, Tangdu Hospital, The Fourth Military Medical University, Xi'an 710038, P.R. China

E-mail: luqiangmd@gmail.com

E-mail: xubz@fmmu.edu.cn

${ }^{*}$ Contributed equally

Key words: Bcl-2 associated athanogene 3, apoptosis, non-small cell lung cancer, Bcl-2 respiratory epithelium cells (3). Among them, non-small cell lung cancer (NSCLC) accounts for approximately $85 \%$ of all lung cancer cases (4). The subtypes of NSCLC are classified into adenocarcinoma, squamous cell carcinoma and large cell carcinoma $(5,6)$. Adenocarcinoma of lung usually develops in the outer area of the lung and often presents as metastatic disease. It can occur in both smokers and non-smokers (7-9). Although treatment options, such as surgery and chemotherapy, have improved, the overall survival of lung adenocarcinoma remains at the original level (10). Lung adenocarcinoma presents specific genomic changes that might be responsible for both the initiation and maintenance of the malignancy (11-13). These investigations highlight the new mechanisms with vital molecules to develop more effective prognosis and treatments.

Bag3 (Bcl-2 associated athanogene 3), also known as CAIR-1 or Bis, is a $74-\mathrm{kDa}$ cytoplasmatic protein. It is a member of Bag protein family and shares with the other members an evolutionarily conserved domain, that binds the ATPase domain of Hsp70 $(14,15)$. Several studies showed that, in human primary lymphoid, myeloblastic leukemias and other neoplastic cell types, Bag3 expression sustains cell survival and underlies resistance to therapy, through down-modulation of apoptosis $(16,17)$. On the contrary, down-modulation of Bag3 primary samples of B-cell chronic lymphocytic leukemia and acute lymphoblastic leukemia results in a dramatic increase of basal as well as drug-induced apoptosis $(16,18)$. In addition, Bag3 expression is induced in different normal cell types in response to cell stressors, such as oxidants, high temperature, heavy metals and HIV-1 infection (17,19-21).

In this study, we explored the expression and apoptosisassociated proteins of Bag3 in human normal bronchial epithelial cells, NSCLC cell lines and tissues. Our research found that Bag3 is expressed in some cell lines and tissues of NSCLC. Moreover, we show that Bag3 can interact with anti-apoptotic Bcl-2 proteins to sustain tumor cells to resist apoptosis progression.

\section{Materials and methods}

Cell culture. Specimens of human bronchial epithelial cells were obtained from the autopsied lungs of patients without respiratory disorders. The study was approved by the Ethics 
Committee of our university and the investigation conformed to the principles outlined in the Declaration of Helsinki. Tissues were dissected and rinsed 5 times in $\mathrm{Ca}^{2+}$ and $\mathrm{Mg}^{2+}$ free HBSS and incubated overnight at $4{ }^{\circ} \mathrm{C}$ in $0.1 \%$ protease solution in Ham's F12 medium containing penicillin (100 U/ $\mathrm{ml})$, streptomycin $(100 \mathrm{U} / \mathrm{ml})$ and fungizone $(1 \mu \mathrm{g} / \mathrm{ml})$. Cells were detached by a gentle jet of $20 \%$ FCS in Ham's F12 medium. The suspension was centrifuged at $1,100 \mathrm{rpm}$ for $8 \mathrm{~min}$, and the cell pellet was resuspended in F12/DMEM medium containing $5 \%$ heat-inactivated FCS, penicillin (10 U/ $\mathrm{ml})$ and streptomycin $(100 \mathrm{U} / \mathrm{ml})$. The medium was changed each day for five days to F12/10X medium and changed on alternate days thereafter. The purity of the cultures and identity of the cells were confirmed by light microscopy and immunocytochemical staining using specific monoclonal antibodies directed against cytokeratin.

BEAS-2B cell line was purchased from ATCC (USA). The cells were cultured in Lechner and LaVeck media (LHC-9) containing retinoic acid (33 $\mathrm{nM})$ and epinephrine $(2.75 \mu \mathrm{M})$. Culture flasks and multi-well plates were coated with LHC-basal media containing BSA $(100 \mu \mathrm{g} / \mathrm{ml})$, collagen $(30 \mu \mathrm{g} / \mathrm{ml})$ and fibronectin $(10 \mu \mathrm{g} / \mathrm{ml})$ for at least $4 \mathrm{~h}$ at $37^{\circ} \mathrm{C}$. The cells were maintained in $75-\mathrm{cm}^{2}$ flasks at $37^{\circ} \mathrm{C}$ and $5 \%$ $\mathrm{CO}_{2}$. Media were replaced every second day, and cells were passaged when $>85 \%$ confluent by washing with $\mathrm{Ca}^{2+}$ and $\mathrm{Mg}^{2+}$ free PBS and digested with $0.05 \%$ trypsin.

HOP-62, EKVX and A549 cells were maintained by Department of Thoracic Surgery, Fourth Military Medical University. Cells were cultured in DMEM medium with $10 \%$ FCS including penicillin/streptomycin.

Plasmid and siRNA construction and transfection. The Bag3 expression plasmid was obtained by cloning Bag3 fulllength cDNA from HOP-62 cell line in the expression vector pcDNA3.1. Lipofectamine (Invitrogen, USA) was used for cell transfection with plasmid.

siRNA transfections were performed using $0.2 \mathrm{nM}$ of Stealth siRNA (Invitrogen, USA) per $10^{7}$ cells (control and Bag3 sense sequence, 5'-AAGGUUCAGACCAUCUUGGAA-3') and Lipofectamine (Invitrogen) according to the manufacturer's protocol. Bag3 siRNA was transfected in Opti-MEM for $4 \mathrm{~h}$. Cells were allowed $24 \mathrm{~h}$ to adhere before performing the experiment.

Immunohistochemistry examination. The expression of Bag3 and Hsp70 protein in NSCLC tissues was detected via immunohistochemistry according to the manufacturer's instructions. Tissues were incubated with primary antibodies against Bag3 and Hsp70 (Santa Cruz Biotechnology, Inc., CA, USA) followed by horseradish peroxidase conjugated secondary antibodies. The results were observed with an Olympus microscope and imaging system (BX51; Olympus, Tokyo, Japan). Image analysis was done with the Scion image analyzer (Scion Corp., Frederick, MD, USA).

Assessment of apoptosis. The cells were washed with PBS and stained with Annexin V/PI (BD Pharmingen) for $30 \mathrm{~min}$ at room temperature, separately. Cells were then processed and analyzed using a Becton-Dickinson FACScan cytofluorometer (Mansfield, USA) with the use of CellQuest software (Becton-
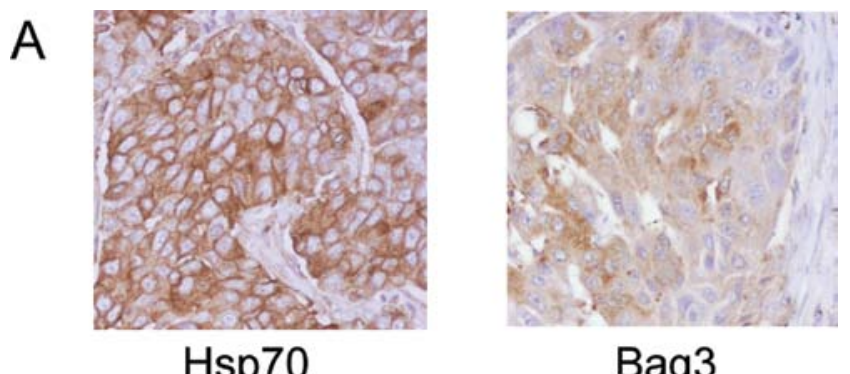

Hsp70

Bag3

B

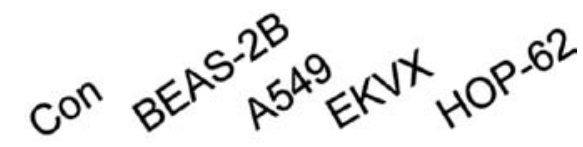

Bag3

Hsp70

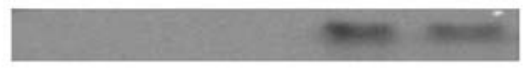

$\beta$-actin

Figure 1. The expression of Bag3 and Hsp70 were detected by immunohistochemistry in NSCLC tissues. (A) Bag3 and Hsp70 were expressed in the cytoplasm in NSCLC cells. (B) Western blotting was performed to show the expression of Bag3 and Hsp70 in human normal bronchial epithelial cells (marked as 'Con'), BEAS-2B, A549, EKVX and HOP-62.

Dickinson, USA). Cells were considered to be apoptotic if they were either Annexin $\mathrm{V}^{+} / \mathrm{PI}^{-}$(early apoptotic) or Annexin $\mathrm{V}^{+} / \mathrm{PI}^{+}$ (late apoptotic).

Quantitative real-time RT PCR. Total RNA was extracted using TRIzol Reagent (Invitrogen) and digested with DNase (Invitrogen). A quantitative RT-PCR assay was performed using the LightCycler 480 SYBR-Green I Master (Roche Diagnostics, GmbH) with a Roche 480 LightCycler. Real-time reactions were performed on a Bio-Rad iCycler. Real-time PCR primers include the following: Bag3 (upper, 5'-CCTTGGACTGAAGGG GTTTT-3'; lower, 5'-ATGGCTCCTTGCATAGCTCATA-3'); Hsp70 (upper, 5'-CACTGTACCAGGGGATTATGTTT-3'; lower, 5'-ATGTAGTACACAGTGCCAAGACG-3'); Bcl-X $_{\mathrm{L}}$ (upper, 5'-ATGGCAGCAGTGAAGCAAGC-3'; lower, 5'-ACGATGCGACCCCAGTTTACTC-3'); Bcl-2 (upper, 5'-GTCGCTACCGTCGTGACTT-3'; lower, 5'-CAGCCTCCGTTATCCTGGA-3'); and $\beta$-actin (upper, 5'-GCTCTTTTCCAGCCTTCCTT-3'; lower, 5'-TGATCCACATCTGCTGGAAG-3'). Each sample was run in triplicate. Primer specificity was confirmed by melting curve analysis and electrophoresis of PCR on a $1.5 \%$ agarose gel to confirm the size of products.

Co-immunoprecipitation and Western blotting. Proteins $(300 \mu \mathrm{g})$ was used for immunoprecipitation assays using $3 \mu \mathrm{g}$ of anti-Bag3 monoclonal antibody (Santa Cruz Biotechnology, Inc.) and incubated at $4^{\circ} \mathrm{C}$ overnight on a tube rotator. Protein A-Sepharose, $25 \mathrm{ml}$, was then added, and the immunocomplexes were precipitated and washed five times with 


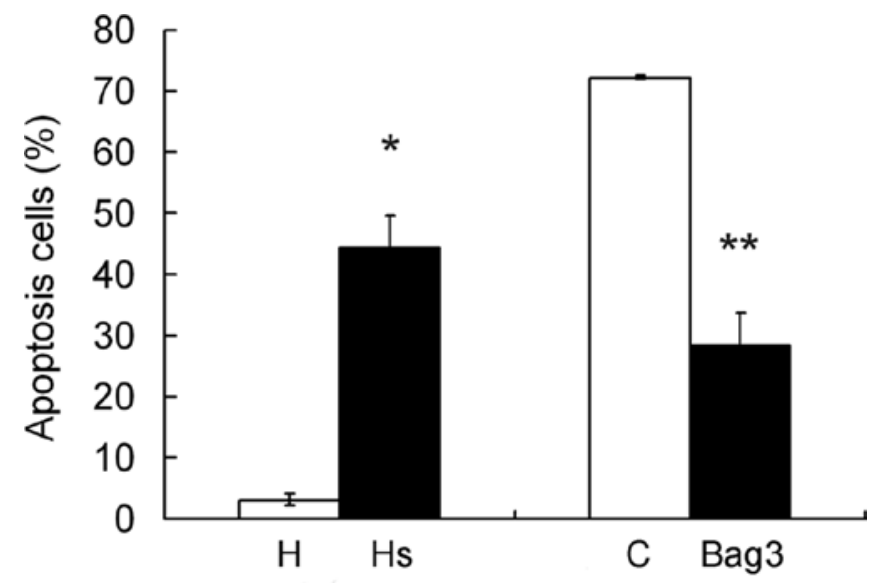

Figure 2. The regulation of Bag3 in apoptosis of NSCLC. Bag3 gene silencing sensitized HOP-62 cells to apoptosis. Bag3 overexpression promoted antiapoptosis in human normal bronchial epithelial cells. "Bag3 interfere group vs. original HOP-62 group, $\mathrm{P}<0.05 ;{ }^{* *} \mathrm{Bag} 3$ overexpression group vs. original human normal bronchial epithelial cell group, $\mathrm{P}<0.05$ ).

radioimmunoprecipitation assay buffer. For Western blot analyses, proteins obtained from immunoprecipitations or $30 \mu \mathrm{g}$ of total protein were run on $10 \%(\mathrm{wt} / \mathrm{vol})$ SDS/PAGE gels and transferred to nitrocellulose. Nitrocellulose blots were blocked and incubated with antibodies against Bag3, Hsp70, Bcl- $\mathrm{X}_{\mathrm{L}}$, Bcl-2 and $\beta$-actin (Santa Cruz Biotechnology, Inc.) followed by horseradish peroxidase conjugated secondary antibodies. Detection was performed by using enhanced chemiluminescence (ECL) (Pierce, USA).

Image analysis and statistical processing. All experimental data are reported as the mean \pm SE. Variance was analyzed with the SPSS statistical software package (version 10.0; SPSS, Chicago, IL, USA), with multiple comparisons verified with the least significant difference t-test. Statistical significance was set at $\mathrm{p}<0.05$.

\section{Results}

Bag3 and Hsp70 were highly expressed in cytoplasm of some NSCLC tissues and cell lines. To describe the expression of Bag3 and Hsp70 in cells and tissues of NSCLC, we identified Bag3 and Hsp70 protein expression by immunohistochemistry in cells and tissues from different types and grades of NSCLC (Fig. 1A). Human normal bronchial epithelial cells and BEAS-2B cell line were detected as normal control. In this experiment, we observed that Bag3 and Hsp70 proteins were expressed in HOP-62 and EKVX cell lines and highly in the cytoplasm in $27.3 \%$ cases of NSCLC (6 in 22 cases). We detected weak Hsp70 and no Bag3 expression in human normal bronchial epithelial cells and BEAS-2B cell line (Fig. 1B).

Bag3 inhibits the apoptosis in human normal bronchial epithelial cell lines in vitro. We investigated the effects of Bag3 silencing in apoptosis of NSCLC cell lines and the overexpression of protein in human normal bronchial epithelial cell lines in vitro. Our results showed that down-regulation of Bag3 in HOP-62 cell line by a specific siRNA resulted in
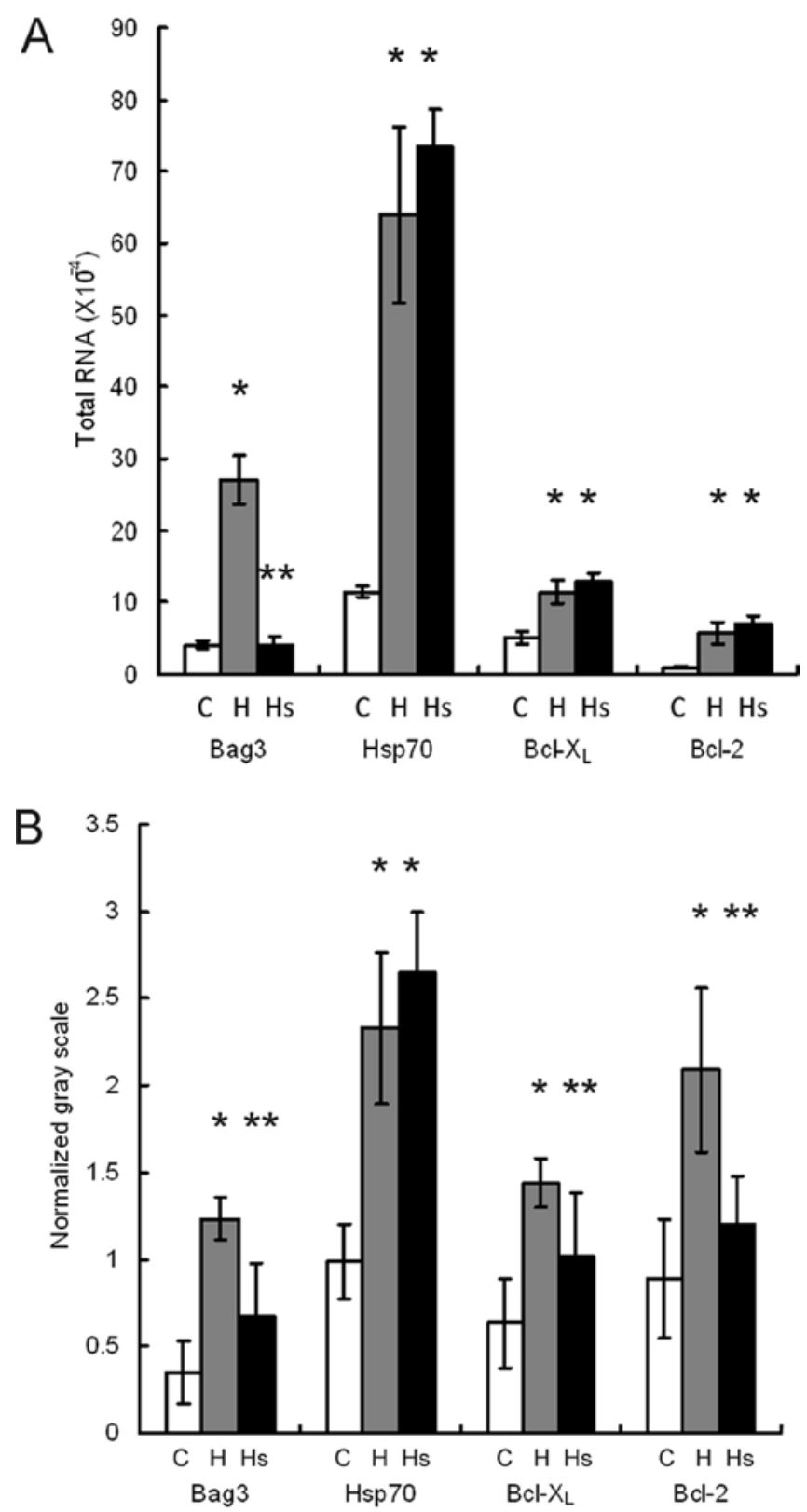

Figure 3. Bag3 gene silencing has no effect on Hsp70, Bcl- $\mathrm{X}_{\mathrm{L}}$ and $\mathrm{Bcl}-2$ on transcription level, neither on the protein expression level (except Hsp70) in NSCLC cells. (A) RT-PCR analysis of Bag3 and other mRNA levels. (B) Western blot analysis of their protein level. *H or Hs group vs. control group, $\mathrm{P}<0.05 ;{ }^{* *} \mathrm{Hs}$ group vs. $\mathrm{H}$ group, $\mathrm{P}<0.05$. (C) Control (human normal bronchial epithelial cells); H, HOP-62; Hs, HOP-62 with Bag3 silencing.

significantly increasing cell apoptosis $(\mathrm{P}<0.05$, Fig. 2). It is consistent that overexpression of Bag3 in human normal bronchial epithelial cells protected cells from apoptosis $(\mathrm{P}<0.05$, Fig. 2). The results confirmed the anti-apoptotic property of Bag3 in NSCLC in vitro.

Bag3, $\mathrm{Hsp} 70, \mathrm{Bcl}-\mathrm{X}_{L}$ and $\mathrm{Bcl}-2$ are up-regulated in NSCLC cell line in vitro. According to previous results, Bag3 inhibits apoptosis in human normal bronchial epithelial cell lines, while the silencing of Bag3 increased the apoptosis in NSCLC cell line. Thus the expression of Bag3 and apoptosis-associated proteins were explored in HOP-62 cell line by RT-PCR and 


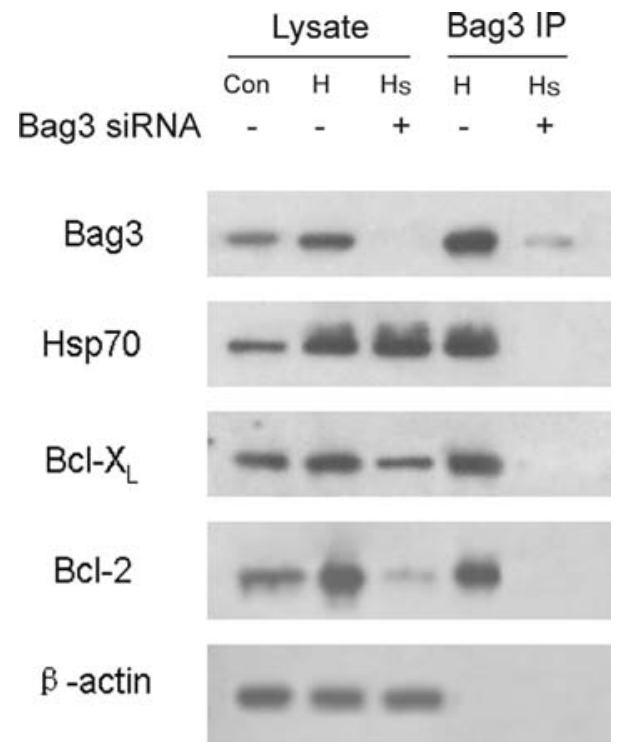

Figure 4. Interactions and regulations among Bag3 and other proteins. Whole lysates from $\mathrm{H}$ and $\mathrm{Hs}$ group cells were immunoprecipitated with the anti-Bag3 antibody IMG-5676 (Imgenex Corp., CA) and analyzed by immunoblotting with anti-Bag3 antibody P-17, anti-Hsp70, anti-Bcl- $\mathrm{X}_{\mathrm{L}}$, anti-Bcl-2 and anti- $\beta$-actin (Santa Cruz Biotechnology, Inc.).

Western blot analysis. The results showed that the production of Bag3, Hsp70, Bcl- $\mathrm{X}_{\mathrm{L}}$ and Bcl-2 in HOP-62 cell line was more than that in human normal bronchial epithelial cell lines on gene transcription and protein translation level ( $\mathrm{P}<0.05$, Fig. 3).

Inhibition of Bag3 results in diminished levels of $B c l-X_{L}$ and $B c l-2$ in NSCLC cell line. In this experiment, we investigated whether silencing Bag3 was responsible for the concomitant decreases in apoptosis-associated proteins in NSCLC cell line. Accordingly, siRNA was used to silence Bag3 and the effect on the expression of $\mathrm{Hsp} 70, \mathrm{Bcl}-\mathrm{X}_{\mathrm{L}}$ and $\mathrm{Bcl}-2$ proteins were examined. Real-time PCR and Western blot analysis showed a significant reduction in Bag3 mRNA and protein levels in cells transfected with Bag3 specific siRNA. Silencing Bag3 did not affect on the gene transcription of $\mathrm{Hsp} 70, \mathrm{Bcl}-\mathrm{X}_{\mathrm{L}}$ and $\mathrm{Bcl}-2$ ( $P>0.05$, Fig. 3A), but it could decrease levels of $\mathrm{Bcl}-\mathrm{X}_{\mathrm{L}}$ and $\mathrm{Bcl}-2$ in protein translation $(\mathrm{P}<0.05$, Fig. $3 \mathrm{~B})$. The inhibition of Bag3 hardly changed the Hsp70. Bag3 was able to interact with Hsp70, Bcl-X $\mathrm{L}_{\mathrm{L}}$ and Bcl-2 in NSCLC cell line by immunoprecipitation.

It has been reported that Bag3 interacts with $\mathrm{Hsp} 70, \mathrm{Bcl}-\mathrm{X}_{\mathrm{L}}$ and Bcl-2 in different tumor cells to inhibit tumor apoptosis (22-24). Therefore, we hypothesized that in NSCLC cell line, Bag 3 can bind to apoptosis-associated proteins to decrease the apoptosis of tumor cells (Fig. 4), coimmunoprecipitation experiments were performed in HOP-62 to confirm the interaction between Bag3 and $\mathrm{Hsp} 70, \mathrm{Bcl}_{\mathrm{L}}$ and $\mathrm{Bcl}-2$. These data imply the existence of a multiprotein complex between Bag3, Hsp70, Bcl- $\mathrm{X}_{\mathrm{L}}$ and $\mathrm{Bcl}-2$ in the NSCLC cell line.

\section{Discussion}

Although NSCLC has been categorized in histology, NSCLC tumors have heterogeneous histology within the same lesion in many cases. Morphology remains the standard for clinical diagnosis and treatment. At the same time, significant effort has recently been dedicated to elucidate the molecular biology of NSCLC to help clinical research to acquire more useful information in the treatment of NSCLC (25-27).

In this study, we demonstrate for the first time that the expression of Bag3 and its effects on the anti-apoptotic proteins in NSCLC tissues and cell lines. The results of IHC indicated that the expression of Bag3 and Hsp70 are up-regulated in some cases of NSCLC. Furthermore, many reports showed that Bag3 expression attenuates apoptosis in a few cancer cells via stabilization of anti-apoptotic Bcl-2 proteins (28-32). We hypothesized that Bag3 could inhibit apoptosis of NSCLC cells by regulating the expression of $\mathrm{Bcl}-2$ and other functional components.

In this study, we cultured human normal bronchial epithelial and NSCLC cell lines for exploring the potential mechanism of Bag3 as an anti-apoptotic in tumor progression. Our results showed that the regulation of Bag3 changed the effect of apoptosis of NSCLC cell line. We found that Bcl-X and $\mathrm{Bcl}-2$ protein expression were significantly reduced, while their mRNA levels were not affected by silencing Bag3 (Figs. 3 and 4). It suggested that this effect of Bag3 is mediated at the level of protein by molecule interaction and degradation (Fig. 4). This style of protein interaction regulation by Bag3 could be effective in modulating different components in several pathways to cooperate on inhibition of apoptosis of tumor cells at the same time.

Our study suggests that Bag3 may be important in the survival and apoptosis in NSCLC. A previous report also showed that Bag3 can regulate the motility and adhesion of epithelial cancer cells (33). Bag3 can interact with different molecules to increase its effect on the progression and invasion in many cancers. Further studies are needed to explore the clinical characteristic of Bag3 in NSCLC. Because of the small number of NSCLC cases (22 cases), further exploring the relationship among the tissue morphology, survival and Bag3 expression was not possible. We will perform associated work to study this further.

In conclusion, we demonstrate that $\mathrm{Bag} 3$ expression is increased in some cases of NSCLC. It was able to inhibit apoptosis of NSCLC cells by interacting with several different apoptosis-associated proteins in vitro. Bag3 may be a good target for developing new methods to improve the survival in NSCLC.

\section{Acknowledgements}

We thank the Department of Thoracic Surgery, Fourth Military Medical University, for excellent technical assistance.

\section{References}

1. Hernandez BY, Green MD, Cassel KD, Pobutsky AM, Vu V and Wilkens LR: Preview of Hawaii cancer facts and figures 2010. Hawaii Med J 69: 223-224, 2010.

2. Jemal A, Siegel R, Ward E, Hao Y, Xu J and Thun MJ: Cancer statistics, 2009. CA Cancer J Clin 59: 225-249, 2009.

3. Brambilla E, Travis WD, Colby TV, Corrin B and Shimosato Y: The new World Health Organization classification of lung tumours. Eur Respir J 18: 1059-1068, 2001. 
4. Youlden DR, Cramb SM and Baade PD: The international epidemiology of lung cancer: geographical distribution and secular trends. J Thorac Oncol 3: 819-831, 2008.

5. Ginsberg MS, Grewal RK and Heelan RT: Lung cancer. Radiol Clin North Am 45: 21-43, 2007.

6. Beasley MB, Brambilla E and Travis WD: The 2004 World Health Organization classification of lung tumors. Semin Roentgenol 40: 90-97, 2005.

7. Webb JD and Simon MC: Novel insights into the molecular origins and treatment of lung cancer. Cell Cycle 9: 4098-4105, 2010.

8. Sun S, Schiller JH and Gazdar AF: Lung cancer in never smokers - a different disease. Nat Rev Cancer 7: 778-790, 2007.

9. Hecht SS: Tobacco carcinogens, their biomarkers and tobaccoinduced cancer. Nat Rev Cancer 3: 733-744, 2003.

10. Bronte G, Rizzo S, La Paglia L, et al: Driver mutations and differential sensitivity to targeted therapies: a new approach to the treatment of lung adenocarcinoma. Cancer Treat Rev 36 (Suppl 3): S21-S29, 2010.

11. Ciardiello F and Tortora G: EGFR antagonists in cancer treatment. N Engl J Med 358: 1160-1174, 2008.

12. Kumar A, Petri ET, Halmos B and Boggon TJ: Structure and clinical relevance of the epidermal growth factor receptor in human cancer. J Clin Oncol 26: 1742-1751, 2008.

13. Engelman JA, Luo J and Cantley LC: The evolution of phosphatidylinositol 3-kinases as regulators of growth and metabolism. Nat Rev Genet 7: 606-619, 2006.

14. Briknarova K, Takayama S, Homma S, et al: BAG4/SODD protein contains a short BAG domain. J Biol Chem 277: 31172-31178, 2002.

15. Sondermann H, Scheufler C, Schneider C, Hohfeld J, Hartl FU and Moarefi I: Structure of a Bag/Hsc70 complex: convergent functional evolution of Hsp70 nucleotide exchange factors. Science 291: 1553-1557, 2001.

16. Romano MF, Festa M, Pagliuca G, et al: BAG3 protein controls B-chronic lymphocytic leukaemia cell apoptosis. Cell Death Differ 10: 383-385, 2003.

17. Bonelli P, Petrella A, Rosati A, et al: BAG3 protein regulates stress-induced apoptosis in normal and neoplastic leukocytes. Leukemia 18: 358-360, 2004.

18. Romano MF, Festa M, Petrella A, et al: BAG3 protein regulates cell survival in childhood acute lymphoblastic leukemia cells. Cancer Biol Ther 2: 508-510, 2003.

19. Pagliuca MG, Lerose R, Cigliano S and Leone A: Regulation by heavy metals and temperature of the human BAG-3 gene, a modulator of Hsp70 activity. FEBS Lett 541: 11-15, 2003.

20. Chen L, Wu W, Dentchev T, et al: Light damage induced changes in mouse retinal gene expression. Exp Eye Res 79: 239-247, 2004
21. Rosati A, Leone A, Del Valle L, Amini S, Khalili K and Turco MC: Evidence for BAG3 modulation of HIV-1 gene transcription. J Cell Physiol 210: 676-683, 2007.

22. Rosati A, Ammirante M, Gentilella A, et al: Apoptosis inhibition in cancer cells: a novel molecular pathway that involves BAG3 protein. Int J Biochem Cell Biol 39: 1337-1342, 2007.

23. Antoku K, Maser RS, Scully WJ Jr, Delach SM and Johnson DE: Isolation of Bcl-2 binding proteins that exhibit homology with BAG-1 and suppressor of death domains protein. Biochem Biophys Res Commun 286: 1003-1010, 2001.

24. Lee JH, Takahashi T, Yasuhara N, Inazawa J, Kamada S and Tsujimoto Y: Bis, a Bcl-2-binding protein that synergizes with Bcl-2 in preventing cell death. Oncogene 18: 6183-6190, 1999.

25. Lau SK, Luthringer DJ and Eisen RN: Thyroid transcription factor-1: a review. Appl Immunohistochem Mol Morphol 10 97-102, 2002

26. Lau SK, Desrochers MJ and Luthringer DJ: Expression of thyroid transcription factor-1, cytokeratin 7, and cytokeratin 20 in bronchioloalveolar carcinomas: an immunohistochemical evaluation of 67 cases. Mod Pathol 15: 538-542, 2002.

27. Zamecnik J and Kodet R: Value of thyroid transcription factorand surfactant apoprotein $\mathrm{A}$ in the differential diagnosis of pulmonary carcinomas: a study of 109 cases. Virchows Arch 440: 353-361, 2002.

28. Ammirante M, Rosati A, Arra C, et al: IKK \{gamma\} protein is a target of BAG3 regulatory activity in human tumor growth. Proc Natl Acad Sci USA 107: 7497-7502, 2010.

29. Jacobs AT and Marnett LJ: HSF1-mediated BAG3 expression attenuates apoptosis in 4-hydroxynonenal-treated colon cancer cells via stabilization of anti-apoptotic Bcl-2 proteins. J Biol Chem 284: 9176-9183, 2009.

30. Wang HQ, Meng X, Gao YY, et al: Characterization of BAG3 cleavage during apoptosis of pancreatic cancer cells. J Cell Physiol 224: 94-100, 2010.

31. Wang HQ, Liu BQ, Gao YY, et al: Inhibition of the JNK signalling pathway enhances proteasome inhibitor-induced apoptosis of kidney cancer cells by suppression of BAG3 expression. Br J Pharmacol 158: 1405-1412, 2009.

32. Du ZX, Meng X, Zhang HY, Guan Y and Wang HQ: Caspasedependent cleavage of BAG3 in proteasome inhibitors-induced apoptosis in thyroid cancer cells. Biochem Biophys Res Commun 369: 894-898, 2008

33. Iwasaki M, Homma S, Hishiya A, Dolezal SJ, Reed JC and Takayama S: BAG3 regulates motility and adhesion of epithelial cancer cells. Cancer Res 67: 10252-10259, 2007. 